Originally published in Analysis (Volume 64, No. 2, April 2004: 122-8). An extended version of this paper appears in chapter 3 of my A Future for Presentism (Oxford University Press, 2006)

(C) Craig Bourne

\title{
Future Contingents, Non-Contradiction and the Law of Excluded Middle Muddle
}

For whatever reason, we might think that contingent statements about the future have no determinate truth value. Aristotle, in De interpretatione IX, for instance, held that only those propositions about the future which are either necessarily true, or necessarily false, or 'predetermined' in some way have a determinate truth-value. This led Łukasiewicz in 1920 to construct a three-valued logic in an attempt to formalize Aristotle's position by giving the truth-value $1 / 2=$ indeterminate to future contingents and defining ' $\sim$ ', ' $\&$ ' and ' $\vee$ ', where $1=$ true and $0=$ false, as:

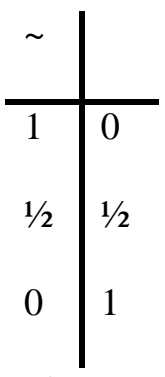

Fig 1: Łukasiewicz Negation

\begin{tabular}{c|ccc}
$\&$ & 1 & $1 / 2$ & 0 \\
\hline 1 & 1 & $1 / 2$ & 0 \\
$1 / 2$ & $1 / 2$ & $1 / 2$ & 0 \\
0 & 0 & 0 & 0
\end{tabular}

Fig 2: Łukasiewicz Conjunction

\begin{tabular}{c|ccc}
$\vee$ & 1 & $1 / 2$ & 0 \\
\hline 1 & 1 & 1 & 1 \\
$1 / 2$ & 1 & $1 / 2$ & $1 / 2$ \\
0 & 1 & $1 / 2$ & 0
\end{tabular}

Fig 3: Łukasiewicz Disjunction 
Originally published in Analysis (Volume 64, No. 2, April 2004: 122-8). An extended version of this paper appears in chapter 3 of my A Future for Presentism (Oxford University Press, 2006)

(C) Craig Bourne

We can see that the purely determinate entries match the tables of the classical two-valued system; thus, what needs justification are the other entries. Let us take negation to illustrate. We may treat indeterminateness as something to be resolved one way or the other: it will eventually be either true or false. Thus the truth-value of the negation of an indeterminate proposition must itself be indeterminate, since if the initial proposition could be resolved either way, so must its negation. This reasoning similarly justifies the ' $1 / 2$ ' entries in the other tables.

Now, this system works smoothly for most cases of future contingent statements. Suppose, for example, I say:

(1) Either I will drown my sorrows or I will buy a Ducati 916 motorcycle.

We would intuitively think that if both of the disjuncts are indeterminate, then the whole disjunction must be indeterminate. This is precisely the answer given by Łukasiewicz's truth-tables. However, the trouble begins when we consider cases where one disjunct is the negation of the other. For suppose I say,

(2) Either I will buy a Ducati or I will not buy a Ducati.

Because there is no middle ground to be had - either I will or I will not buy a Ducati - we must agree that (2) is determinately true. The problem is that both disjuncts are future contingent propositions and therefore indeterminate; but then, according to Łukasiewicz's tables, the whole disjunction must be indeterminate. Łukasiewicz's system gives us the wrong answer.

But not only is the law of excluded middle ( $p \vee \sim p$ ) no longer a logical truth in this system, the law of non-contradiction $(\sim(p \& \sim p))$ isn't either, for it too takes the value $1 / 2$ when $p=1 / 2$. Furthermore, this system cannot be the correct formalization of Aristotle either, since, as noted above, necessary truths such as $(p \vee \sim p)$ for Aristotle have the determinate value $=$ true. 
Originally published in Analysis (Volume 64, No. 2, April 2004: 122-8). An extended version of this paper appears in chapter 3 of my A Future for Presentism (Oxford University Press, 2006)

(C) Craig Bourne

So was Aristotle just horribly confused in thinking it is possible to have a non-bivalent logic whilst retaining as logical truths the laws of excluded middle and non-contradiction? W. \& M. Kneale (1962: 47ff) think so, and Quine calls Aristotle's desire ‘fantasy'. I disagree: adopting a non-bivalent logic does not have to result in our abandoning the laws of excluded middle and non-contradiction. In light of our discussion so far, there are two options for a solution to this problem: either we adopt Łukasiewicz's system and drop some other assumption, or we construct some new system.

Tooley (1997) opts for the first. He adopts Łukasiewicz's system, but the assumption he drops is that the connectives in three-valued logic are truth-functional. This is because, for instance, some disjunctions $(p \vee q)$ with indeterminate disjuncts are indeterminate, whereas others $(p \vee \sim p)$ are determinately true. So the truth-value of the whole sentence in three-valued logic is not a function of its component parts. This is a quite natural reaction: some sentences, we may think, just are different from others because they are true simply in virtue of their form (what Tooley calls 'logical truths' (p.139)), whereas others require truthmakers external to the proposition to make them true (what Tooley calls 'factual truths' (p.139)).

But although this solution might initially appeal, it is not a satisfactory one. For we are left wondering why it is that such sentences have a privileged status in three-valued logic. What is so special about these sentences that Tooley feels warranted in holding them to be determinately true in order to draw the conclusion that the connectives in three-valued logic must therefore be non-truthfunctional? Certainly, they are logical truths in two-valued logic; they are true under all assignments of truth-values to the component parts and this is what justifies us in privileging them. But given the truth-tables for the connectives in three-valued logic, the sentences ' $p \vee \sim p$ ' and ' $\sim(p \& \sim p)$ ' are not true under all possible interpretations; they are not 'true in virtue of their form', so in what sense are they logical truths? In other words, why does Tooley think they are necessary truths given he thinks the world is governed by three-valued logic? I cannot see any.

Thus, we should take the second option: construct a different system to Łukasiewicz's. The following systems allow us to keep the connectives truth-functional, allow us to keep the laws of excluded middle and non-contradiction as logical truths, they don't introduce a distinction between 
Originally published in Analysis (Volume 64, No. 2, April 2004: 122-8). An extended version of this paper appears in chapter 3 of my A Future for Presentism (Oxford University Press, 2006)

(C) Craig Bourne

logical and factual truths, and they allow us to keep the notion of logical truth as true under all interpretations, both for two- and three-valued logic. All this and non-bivalence! This, then, is something along the lines that we've been after.

The solution rests on the following observation: it is the definition of ' $\sim$ ' that causes the trouble. Thus we should stop trying to patch up the obvious deficiencies in Łukasiewicz's system (as Tooley does) and deal with the root directly. For not only does Łukasiewicz's definition of ' $\sim$ ' create the difficulty, I see no reason to think that it is correct, and thus altering it is not fudging it. I claim that the following truth-table is more suitable:

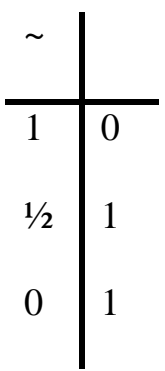

Fig 4: Improved Negation

The justification for the $\sim(1 / 2)=1$ entry is as follows: given that $p$ is indeterminate, then it isn't the case that $p$; so to say that it is not the case that $p$ is clearly to say something true. Thus, there is no justification for holding that the negation of a proposition can only be true if that proposition is false, as in Łukasiewicz's system.

Such a definition of ' $\sim$ ' is employed in Bochvar's (1938) 'external' system, which also defines ' $\&$ ' and ' $\vee$ ' as:

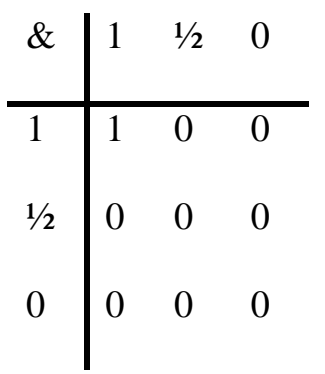

Fig 5: Bochvar Conjunction 
Originally published in Analysis (Volume 64, No. 2, April 2004: 122-8). An extended version of this paper appears in chapter 3 of my A Future for Presentism (Oxford University Press, 2006)

(C) Craig Bourne

\begin{tabular}{c|lll}
$\vee$ & 1 & $1 / 2$ & 0 \\
\hline 1 & 1 & 1 & 1 \\
$1 / 2$ & 1 & 0 & 0 \\
0 & 1 & 0 & 0
\end{tabular}

Fig 6: Bochvar Disjunction

Bochvar used this for the purpose of solving certain paradoxes of classical logic and set theory, and Halldén (1949) uses these tables to develop systems for dealing with vagueness and the logic of nonsense; so it is a system that is well understood. Moreover, it is a three-valued system where the classical laws remain valid. However, there are serious disadvantages to the Bochvar truth-tables for our purposes. For if we adopt these truth-tables, why is it that under composition we lose indeterminate truth-values? There are good reasons for Bochvar's purposes why this occurs, but his concerns are not ours. For the purposes of constructing a plausible system for future contingents, as we saw in (1) above, we want certain compound sentences with indeterminate components to remain indeterminate. This is not the system for us.

However, the solution now is clear. As noted, it was the definition of ' ' in Łukasiewicz's system that caused the trouble. But, as we have seen with (1), the rest of Łukasiewicz's system works well. So, if we construct a system based on these two desirable features, then the laws of noncontradiction and excluded middle remain logical truths - and, moreover, fall out as natural consequences of intuitive independent reasoning, unlike with Tooley's reasoning -, and the truthvalues of molecular propositions remain intuitive. Thus, those who wish to keep hold of a nonbivalent logic for future contingents can do so plausibly without having to abandon those logical laws, by working with the following truth-tables: 
Originally published in Analysis (Volume 64, No. 2, April 2004: 122-8). An extended version of this paper appears in chapter 3 of my A Future for Presentism (Oxford University Press, 2006)

(C) Craig Bourne

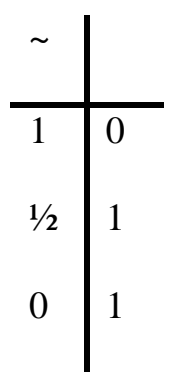

Fig 4: Improved negation

\begin{tabular}{c|ccc}
$\&$ & 1 & $1 / 2$ & 0 \\
\hline 1 & 1 & $1 / 2$ & 0 \\
$1 / 2$ & $1 / 2$ & $1 / 2$ & 0 \\
0 & 0 & 0 & 0
\end{tabular}

Fig 2: Łukasiewicz Conjunction

\begin{tabular}{c|ccc}
$\vee$ & 1 & $1 / 2$ & 0 \\
\hline 1 & 1 & 1 & 1 \\
$1 / 2$ & 1 & $1 / 2$ & $1 / 2$ \\
0 & 1 & $1 / 2$ & 0
\end{tabular}

Fig 3: Łukasiewicz Disjunction

I also take it that the most uncontroversial reading of ' $\mathrm{P} \supset \mathrm{Q}$ ' is ' $\sim(\mathrm{P} \& \sim \mathrm{Q})$ ', in which case:

\begin{tabular}{l|lll}
$\supset$ & 1 & $1 / 2$ & 0 \\
\hline 1 & 1 & 0 & 0 \\
$1 / 2$ & 1 & 1 & 1 \\
0 & 1 & 1 & 1
\end{tabular}

Fig 7: Material Conditional 
Originally published in Analysis (Volume 64, No. 2, April 2004: 122-8). An extended version of this paper appears in chapter 3 of my A Future for Presentism (Oxford University Press, 2006)

(C) Craig Bourne

Some comment, however, is in order. Let $\mathbf{F}$ (read 'It will be the case that') be a future-tense operator on present-tense propositions. Take the proposition

(3) Dr Foster will go to Gloucester

and the proposition

(4) Dr Foster will not go to Gloucester.

It may be thought if one assigns $1 / 2$ to (3), then (4) must be assigned the value 1 - even if Dr Foster does end up going to Gloucester! So what has gone wrong? Nothing, I say; and this is obvious so long as we understand these propositions correctly. Obviously, proposition (3) is to be analysed as follows:

$\left(3^{*}\right) \quad \mathbf{F}($ Dr Foster goes to Gloucester)

Care must be taken, however, when analysing (4) if we require it to be the negation of (3). The incorrect analysis is where the future-tensed operator has wide scope over the present-tensed proposition:

(4×) $\quad$ F $\sim($ Dr Foster goes to Gloucester).

The reason why this must be the incorrect analysis of the negation of (3) is clear: the present-tensed proposition that Dr Foster goes to Gloucester has a determinate truth-value - it is either true or false depending on whether there is a present fact that Dr Foster goes to Gloucester to make it true. The negation of this proposition - Dr Foster does not go to Gloucester - is likewise either determinately true or false. But because these propositions fall within the future-tensed operator, both $\left(3^{*}\right)$ and $(4 \times)$ as a whole have the value 'indeterminate'. Now, this does not destroy the law of excluded middle 
Originally published in Analysis (Volume 64, No. 2, April 2004: 122-8). An extended version of this paper appears in chapter 3 of my A Future for Presentism (Oxford University Press, 2006)

(C) Craig Bourne

because the future-tensed proposition (4x), i.e., $(4 \times)$ taken as a whole, is not the negation of the future-tensed proposition $\left(3^{*}\right)$, i.e., $\left(3^{*}\right)$ taken as a whole - it matters not a jot that the embedded present-tensed proposition in $(4 \times)$ is the negation of the embedded present-tensed proposition in $\left(3^{*}\right)$. We may as well represent $\left(3^{*}\right)$ as $p$ and $(4 \times)$ as $q$ to highlight the fact that the pair $\left(3^{*}\right)$ and $(4 \times)$ is no counterexample to $(p \vee \sim p)$. The correct analysis of the negation of (3) is:

\section{$\sim \mathbf{F}$ (Dr Foster goes to Gloucester)}

which is of the form $\sim p$, as required. It seems to me that $\left(4^{*}\right)$ clearly says something true, given that it isn't the case that $p$. But, of course, to say (4*) is true is not to say that Dr Foster won 't go to Gloucester. That would be to confuse $\left(4^{*}\right)$ with $(4 \times)$, which would be a howler: to say that it is not the case that $p$ is not to say that $q$ ! Thus even if it turns out that Dr Foster does go to Gloucester, we should still be happy to assign truth to $\left(4^{*}\right)$. (It might still be misleading to assert the truth of $\left(4^{*}\right)$ because of scope ambiguity and the rest (see, e.g., Grice (1989: Part I)), but this in no way invalidates my reasoning.)

This helps us deal with a slightly different problem. Consider:

(5) $\quad \mathbf{F}(p \vee \sim p)$

Since $(p \vee \sim p)$ falls within the future-tense operator, does this mean we should assign (5) an indeterminate truth-value? Thankfully not, since (5) is clearly true. The reason why not is that the future-tense operator only renders statements indeterminate when it operates on contingent propositions; thus, since logical truths are a species of necessary truth, (5) is true. And my reasons for saying $(p \vee \sim p)$ is a logical truth are the very reasons given above. What this means is that we cannot accept the equivalence:

(6) $\quad \mathbf{F}(p \vee q) \equiv \mathbf{F} p \vee \mathbf{F} q$ 
Originally published in Analysis (Volume 64, No. 2, April 2004: 122-8). An extended version of this paper appears in chapter 3 of my A Future for Presentism (Oxford University Press, 2006)

(C) Craig Bourne

which we should be happy to reject, since if we take $q=\sim p$ we can see (6) mistakenly equates $(4 \times)$ with $\left(4^{*}\right)$.

This system has recognisably classical features: from simple truth-table tests we can see ' $\&$ ' and ' $\vee$ ' are both commutative and associative; 'PつP' is true (unlike Łukasiewicz's and Bochvar's full systems!) ${ }^{1}$; ' $\mathrm{P} \supset \mathrm{Q}$ ' is equivalent to ‘ $\mathrm{Q} \supset \sim \mathrm{P}$ '; the distributive laws $[(\mathrm{P} \vee(\mathrm{Q} \& \mathrm{R})) \equiv((\mathrm{P} \vee \mathrm{Q}) \&(\mathrm{P} \vee \mathrm{R}))$ and $(\mathrm{P} \&(\mathrm{Q} \vee \mathrm{R})) \equiv((\mathrm{P} \& \mathrm{Q}) \vee(\mathrm{P} \& \mathrm{R}))]$ hold; and a form of de Morgan's laws hold $[(\sim(\mathrm{P} \& \mathrm{Q}) \equiv(\sim \mathrm{P} \vee \sim \mathrm{Q}))$ and $\sim(\mathrm{P} \vee \mathrm{Q}) \equiv(\sim \mathrm{P} \& \sim \mathrm{Q})]$, although because of the definition of negation, we lose the equivalence between ' $\&$ ' and ' $\vee$ ' of the form ' $\mathrm{P} \& \mathrm{Q} \equiv \sim(\sim \mathrm{P} \vee \sim \mathrm{Q})$ ' and ' $\sim(\sim \mathrm{P} \& \sim \mathrm{Q}) \equiv(\mathrm{P} \vee \mathrm{Q})$ ', as well as the equivalence $'(\sim \mathrm{P} \vee \mathrm{Q}) \equiv(\mathrm{P} \supset \mathrm{Q})$ ' because of the case where $\mathrm{P}=1$ and $\mathrm{Q}=1 / 2$. It must also be said that, as with many many-valued systems (including Łukasiewicz’s before Słupecki’s (1936) work) this system is not functionally complete. But the sorts of truth-functions that cannot be generated by the connectives of this system have no application anyway, and so can be ignored.

Thus, so long as Dr Foster doesn't fall into a muddle with the law of excluded middle, it is possible to have what my 'Aristotle' desires, namely a non-bivalent logic where classical laws remain intact. Thus it should really be this system and not Łukasiewicz's, as Prior (1953: 317) has it, which is known as the 'classical system of three-valued logic'.2

\footnotetext{
${ }^{1}$ [This is a mistake. It appeared both in Analysis and A Future for Presentism. The correction and what should be said about it is given in Bourne (2010)]

${ }^{2}$ Many thanks to Jeremy Butterfield, Oren Goldschmidt, Hugh Mellor and Peter Smith for various comments. Thanks also to the British Academy's Arts and Humanities Research Board (AHRB) for funding some of this work, and the Master and Fellows of St. Catharine's College, Cambridge, where I completed this work as a Research Fellow
} 
Originally published in Analysis (Volume 64, No. 2, April 2004: 122-8). An extended version of this paper appears in chapter 3 of my A Future for Presentism (Oxford University Press, 2006)

(C) Craig Bourne

\section{$\underline{\text { References }}$}

Aristotle, De interpretatione, trans. E. M. Edghill from The Works of Aristotle, ed. W. D. Ross

(Chicago: Encyclopædia Britannica, Inc., 1952)

Bochvar, D. A., (1938) 'Ob odnom tréhznacnom iscislénii i égo priménénii k analizu paradosov klassičéskogo rasširennogo funkcjonal'noga isčislénia (On a Three-Valued Calculus and its Application to Analysis of Paradoxes of Classical Extended Functional Calculus)', Matématicéskij Sbornik, 4, 287-308.

Bourne, C. (2010) 'Fatalism and the Future' in C.Callender (ed.) The Oxford Handbook of Time (Oxford: Oxford University Press)

Grice, P., (1989) Studies in the Way of Words (Cambridge, Mass.; London: Harvard University Press)

Halldén, S., (1949) The Logic of Nonsense (Uppsala: Uppsala Universitets Arsskrift).

Jackson, F. (1987) Conditionals (Oxford: Blackwell)

Kneale, W. \& M., (1962) The Development of Logic (Oxford: Clarendon Press)

Łukasiewicz, J., (1920) 'On Three-Valued Logic', in S. McCall (ed.), Polish Logic 1920-1939

(Oxford: Clarendon Press, 1967), 16-18. Also in Selected Works, edited by L. Borkowski (Amsterdam: North Holland, 1970), 87-8. 
Originally published in Analysis (Volume 64, No. 2, April 2004: 122-8). An extended version of this paper appears in chapter 3 of my A Future for Presentism (Oxford University Press, 2006)

(C) Craig Bourne

Prior, A. N., (1953) ‘Three-Valued Logic and Future Contingents', Philosophical Quarterly, 3, 31726.

Słupecki, J., (1936) 'Der Volle Dreiwertige Aussagenkalkül', Comptes Rendus des Séances de la Société des Sciences et des Lettres de Varsovie Cl. III, 29, 9-11; English trans. 'The Full ManyValued Propositional Calculus', in S. McCall (ed.), Polish Logic 1920-1939 (Oxford: Clarendon Press, 1967), 335-7.

Tooley, M., (1997) Time, Tense, and Causation (Oxford: Oxford University Press) 